\title{
Characteristics, practice patterns, and outcomes in patients with acute hypertension: European registry for Studying the Treatment of Acute hyperTension (Euro-STAT)
}

Alain Vuylsteke ${ }^{1 *}$, Jean-Louis Vincent ${ }^{2}$, Didier Payen de La Garanderie ${ }^{3}$, Frederick A Anderson ${ }^{4}$, Leigh Emery ${ }^{5}$, Allison Wyman ${ }^{4}$, Sophie Rushton-Smith ${ }^{4}$ and Joel M Gore ${ }^{4}$, for the Euro-STAT Investigators

\begin{abstract}
Introduction: Although effective strategies are available for the management of chronic hypertension, less is known about treating patients with acute, severe elevations in blood pressure. Using data from the European registry for Studying the Treatment of Acute hyperTension (Euro-STAT), we sought to evaluate 'real-life' management practices and outcomes in patients who received intravenous antihypertensive therapy to treat an episode of acute hypertension.

Methods: Euro-STAT is a European, hospital-based, observational study of consecutive adult patients treated with intravenous antihypertensive therapy while in the emergency department, perioperative unit or ICU. Enrolment took place between 1 July and 15 October 2009 in 11 hospitals in 7 European countries (Austria, Belgium, Germany, Italy, Spain, Sweden and the United Kingdom).

Results: The study population was composed of 791 consecutive patients (median age 69 years, 37\% women). Median arterial blood pressure before treatment was $166 \mathrm{mmHg}$ systolic blood pressure (IQR 141 to $190 \mathrm{mmHg}$ ) and $80 \mathrm{mmHg}$ diastolic blood pressure (IQR 68 to 95). Nitroglycerine was the most commonly used antihypertensive treatment overall (40\% of patients), followed by urapidil (21\%), clonidine (16\%) and furosemide (8\%). Treatment was associated with hypotension in almost $10 \%$ of patients. Overall 30 -day mortality was $4 \%$, and new or worsening end-organ damage occurred in 19\% of patients.

Conclusions: High blood pressure requiring intravenous therapy is currently managed with a variety of agents in Europe, with those most commonly used being nitroglycerine, urapidil and clonidine. Patients with acute hypertension have substantial concomitant morbidity and mortality, and intravenous antihypertensive treatment is associated with hypotension in almost $10 \%$ of cases.
\end{abstract}

\section{Introduction}

Over 1 billion people worldwide are estimated to have hypertension [1,2], which increases their risk of cardiovascular morbidity and mortality $[3,4]$ and organ injury $[5,6]$. One percent of all hypertensive patients experience at least one episode of acute, severe hypertension, necessitating intravenous (IV) antihypertensive therapy

\footnotetext{
* Correspondence: a.vuylsteke@nhs.net

'Department of Anaesthesia \& Intensive Care, Papworth Hospital NHS

Foundation Trust, Papworth Everard, Cambridge, CB23 3RE, UK

Full list of author information is available at the end of the article
}

and placing these patients at risk of overt, acute endorgan damage over their lifetime. The actual prevalence may in fact be much higher $[7,8]$. One-fourth of patients who present to busy emergency departments (EDs) have acute, severe hypertension $[7,8]$. In the present study, we defined this population by using a pragmatic approach according to whether the treating physicians decided to use IV antihypertensive therapy.

Multiple effective strategies are used for the management of chronic hypertension [1], but less is known about treating patients who present with acute, severe

\section{C) Biomed Central}


elevations in arterial blood pressure (BP). The optimal target for BP lowering has yet to be defined; the definitions of hypertensive urgencies, emergencies and outcome measures lack uniformity; evidence supporting the use of one drug over another is lacking; and whether certain treatments are better than others is unknown [7]. As a consequence, treatment practices vary [9]. The European registry for Studying the Treatment of Acute hyperTension (Euro-STAT) was conducted to evaluate 'real-life' management practices and outcomes in patients treated with IV antihypertensive therapy for an episode of acute hypertension.

\section{Methods}

\section{Study design}

Euro-STAT is a European, hospital-based, observational study of consecutive patients treated with IV antihypertensive therapy while in the critical care setting. Enrolment took place between 1 July and 15 October 2009 in 11 hospitals in 7 European countries (Austria, Belgium, Germany, Italy, Spain, Sweden and the United Kingdom).

The study sites were selected to include a mix of public and private hospitals across a broad geographic area to ensure a rich and diverse population of patients (Table 1). Participating sites had institutional research board approval for the study and adhered to local regulatory and ethical rules. Patient consent was waived in Austria, Belgium, Germany, Italy, Sweden and the United Kingdom, and oral patient consent was required in Spain. The registry was conducted in accordance with European Union directives on the protection of human subjects in research, local ethical guidelines and the Guidelines for Good Epidemiological Practice http:// www.ieaweb.org/index.php?view =article\&catid=20:goodepidemiological-practice-gep\&id=15:good-epidemiological-practice-gep\&format=pdf\&option=com_content\&Ite$\operatorname{mid}=43$. The patients provided their written informed consent to participate if required to do so by local ethical committees. As Euro-STAT is an observational registry, no specific treatments, tests or procedures were mandated or withheld from the patients.

\section{Study objectives}

The objectives of the registry were (1) to improve the understanding of the characteristics of patients with acute BP elevation cared for in EDs, perioperative units and ICUs; (2) to describe contemporary IV management practices, including the timing of treatment initiation, medications used to control $\mathrm{BP}$ within selected ranges and the time required to achieve BP control; and (3) to determine in-hospital and postdischarge outcomes as they relate to the management of an episode of acute hypertension. A preliminary goal was to establish the rates of key variables, which could then be used to develop formal sample size estimates for a planned larger study in the same setting.

\section{Patient selection and enrolment criteria}

Consecutive adult male and female patients at least 18 years of age with a qualifying episode of acute hypertension on or after 1 July 2009 were identified by trained data abstractors through prospective identification of patients admitted to EDs, perioperative units and ICUs. To qualify for enrolment, a patient had to meet the following two criteria: (1) The clinician had to have attempted BP control with either an IV infusion or at least two IV boluses of an antihypertensive drug, and (2) the initial treatment had to have been started within 24 hours of the patient's arrival in the ED, at any time during the perioperative period (defined as the time from the initiation of anaesthesia to discharge from the postanaesthesia recovery area) or within 14 days of ICU admission.

Patients were excluded from participating in the study if they had received IV antihypertensive treatment

Table 1 Sites and investigators participating in Euro-STAT

\begin{tabular}{lll}
\hline Country & Site & National coordinator/investigator \\
\hline Austria & AKH General Hospital & Michael J Hiesmayr \\
Belgium & Erasme University Hospital & Jean-Louis Vincent \\
Germany & Universitätsklinik Bonn & Andreas Hoeft \\
Germany & Charité-Universitätsmedizin & Claudia Spies \\
Italy & Università degli Studi di Firenze & A Raffaele De Gaudio \\
Italy & Sant'Andrea Hospital & Salvatore Di Somma \\
Spain & Hospital de Sabadell & Antonio Artigas \\
Sweden & Karolinska Universitetssjukhuset, Solna & Jan Ostergren \\
United Kingdom & New Cross Hospital Wolverhampton & Giampaolo Martinelli \\
United Kingdom & Papworth Hospital NHS Trust & Alain Vuylsteke \\
United Kingdom & Southampton General Hospital & David Smith
\end{tabular}

Euro-STAT, European registry for Studying the Treatment of Acute hyperTension; NHS, National Health Service. 
initiated in a transferring hospital, if they were admitted for burn treatment, if they had drug-induced (iatrogenic) hypertension, if the qualifying event had occurred while being treated with comfort measures only, and if medical records were not available. ED patients were excluded if they were transferred directly from the ED to another healthcare facility after initiation of IV antihypertensive treatment. Perioperative patients were excluded if they had planned perioperative controlled hypotension and if the qualifying event occurred before the induction of anaesthesia.

\section{Data acquisition}

All eligible patients were assigned a unique study identification number, and abstractors completed a standardised case report form that had been piloted and subsequently validated. Data were abstracted from hospital medical records.

\section{Outcome measures}

The main clinical outcome measures were all-cause inhospital mortality, end-organ injury (including ischaemic stroke, encephalopathy (defined as acute mental status changes without other identifiable causes), acute coronary syndrome, congestive heart failure, renal insufficiency ('chronic kidney failure' was defined as previously diagnosed renal insufficiency or documentation of creatinine clearance less than $60 \mathrm{ml} /$ minute before admission) and aortic dissection), and survival at 30 days following hospital discharge.

\section{Data quality and management}

Training material and guidelines for data abstractors were developed by the data-coordinating centre at the Center for Outcomes Research (COR) at the University of Massachusetts Medical School (Worcester, MA, USA). A one-day course was held at each enrolling hospital to maintain common definitions, improve data abstraction and address training needs.

Data were collected, handled and analysed independently of the sponsor by the data-coordinating centre. Study coordinators at COR reviewed the data collection forms to identify variances from norms and missing data and followed up with the principal investigators by mail or by telephone to resolve any queries.

\section{Statistical analyses}

Descriptive statistics were calculated for all patients. Data are summarised as means $( \pm \mathrm{SD})$ or as medians ( $25 \%$ and $75 \%$ percentiles) for continuous data and as counts and percentages for categorical data. All results shown are univariate and unadjusted. No variable had a level of missing data greater than $10 \%$. Any missing data were simply excluded from the analyses. All eligible patients underwent chart review, and there was no loss to follow-up. Patients' charts were reviewed until the patient's death or discharge from the hospital up to 30 days after initiation of IV antihypertensive therapy (whichever came first). Statistical analyses were performed using the SAS version 9.2 software package (SAS Institute, Cary, NC, USA).

\section{Results}

\section{Overview of study population}

The study population comprised 791 consecutive patients with a median age of 69 years, and $37 \%$ were women (Table 2). In the overall cohort, $62 \%$ had a history of hypertension, $24 \%$ had diabetes mellitus, $14 \%$ had undergone previous cardiac surgery (including coronary artery bypass graft or valve surgery) and $12 \%$ had had a prior myocardial infarction. Patients who were treated during the perioperative period were the youngest and had the highest numerical rates of peripheral vascular disease, tobacco smoking and alcohol misuse compared with the other patients. Patients admitted to the ED were older than the postoperative and ICU populations. The prevalence of history of hypertension (including prior hospitalisation for hypertension), diabetes, neurological disease or dysfunction, chronic kidney disease and end-stage kidney disease was numerically highest among the ED population. The ICU population had the highest prevalence of cardiac surgery and previous myocardial infarction.

The overall median (IQR) initial and peak creatinine values were $89 \mu \mathrm{mol} / \mathrm{L}$ ( 72 to $113 \mu \mathrm{mol} / \mathrm{L}$ ) and 103 $\mu \mathrm{mol} / \mathrm{L}$ (82 to $146 \mu \mathrm{mol} / \mathrm{L}$ ), and these values were highest among patients admitted to the ED and lowest among perioperative patients. The median (IQR) arterial pressure at the initiation of treatment was $166 \mathrm{mmHg}$ for systolic blood pressure (SBP) (141 to $190 \mathrm{mmHg}$ ) and $80 \mathrm{mmHg}$ for diastolic blood pressure (DBP) (68 to $95 \mathrm{mmHg}$ ) (Table 3). The initial BP values were highest among the ED patients.

\section{Intravenous antihypertensive drugs}

The median number (IQR) of IV antihypertensive drugs used during the first three hours was 1 (1 to 2 ) overall and was similar across the clinical settings: 1 (1 to 2 ) in ED and perioperative patients and 1 (1 and 1$)$ in ICU patients. The four most frequently used IV antihypertensive drugs in each clinical setting are shown in Figure 1. Nitroglycerine was the most commonly used drug overall ( $40 \%$ of patients), driven largely by its high rate of use among ICU patients (60\%). Urapidil and clonidine were the next most frequently used drugs overall, which was due to the high rates of use among perioperative patients. Furosemide was the fourth most often used drug and the most commonly used treatment in the ED 
Table 2 Baseline characteristics of the study population

\begin{tabular}{|c|c|c|c|c|}
\hline \multirow[t]{2}{*}{ Variables } & \multirow{2}{*}{$\begin{array}{l}\text { All patients } \\
(N=791)\end{array}$} & \multicolumn{3}{|c|}{ Enrolment setting } \\
\hline & & $\begin{array}{c}\text { ED } \\
(n=180)\end{array}$ & $\begin{array}{c}\text { ICU } \\
(n=382)\end{array}$ & $\begin{array}{c}\text { Perioperative } \\
\quad(n=229)\end{array}$ \\
\hline Median age, years (IQR) & 69 (58 to 77 ) & 70 (60 to 79$)$ & 69 (59 to 76$)$ & 66 (53 to 76$)$ \\
\hline Females, $n(\%)$ & $295(37)$ & $94(52)$ & $107(28)$ & $94(41)$ \\
\hline \multicolumn{5}{|l|}{ Medical history, n (\%) } \\
\hline Hypertension & $491(62)$ & $126(70)$ & $230(60)$ & $135(59)$ \\
\hline Hospitalisation for hypertension & $7(0.9)$ & $6(3.3)$ & $0(0.0)$ & $1(0.4)$ \\
\hline Cardiac surgery & $108(14)$ & $6(3.3)$ & $71(19)$ & $31(14)$ \\
\hline Myocardial infarction & $96(12)$ & $19(11)$ & $56(15)$ & $21(9.2)$ \\
\hline Diabetes mellitus & $189(24)$ & $49(27)$ & $88(23)$ & $52(23)$ \\
\hline Chronic kidney disease & $80(10)$ & $25(14)$ & $43(11)$ & $12(5.2)$ \\
\hline End-stage renal disease & $18(2.3)$ & $5(2.8)$ & $10(2.6)$ & $3(1.3)$ \\
\hline Neurological dysfunction or disease & $91(12)$ & $29(16)$ & $45(12)$ & $17(7.4)$ \\
\hline Peripheral vascular disease & $91(12)$ & $13(7.2)$ & $47(12)$ & $31(14)$ \\
\hline Tobacco smoker & $176(22)$ & $30(17)$ & $83(22)$ & $63(28)$ \\
\hline Alcohol misuse ( $\geq 2$ drinks/day) & $45(5.7)$ & $2(1.1)$ & $23(6.0)$ & $20(8.7)$ \\
\hline Drug abuse (amphetamines, cocaine, other) & $2(0.3)$ & $1(0.6)$ & $1(0.3)$ & $0(0.0)$ \\
\hline \multicolumn{5}{|l|}{ Predisposing factors, $n(\%)$} \\
\hline Medication nonadherence (ED) & - & $11(6.1)$ & - & - \\
\hline Medications withheld > 12 hours (ICU and perioperative) & - & - & $39(10)$ & $21(9.2)$ \\
\hline
\end{tabular}

ED, emergency department; -, no data.

population. Among the ED patients whose first IV treatment was nitroglycerine, hypertension was the most common admitting diagnosis $(n=16,33 \%)$, followed by acute coronary syndrome $(n=8,16 \%)$, chest pain, and heart failure or pulmonary oedema (both $n=6,12 \%$ ).

In each group, more than $90 \%$ of patients achieved a $10 \%$ decrease in SBP within the first 72 hours following initiation of IV antihypertensive therapy. The median time to $10 \%$ decrease was 28 minutes after starting the antihypertensive drug. The following is the breakdown of patients who did not achieve a 10\% decrease within 72 hours: 6 of 180 ED patients (3.3\%), 22 of 382 ICU patients $(5.8 \%)$ and 8 of 229 perioperative patients (3.5\%).

\section{Emergency department patients}

Among the 180 patients who presented to the ED, the most common symptoms were shortness of breath $(n=$ $60,33 \%)$ and chest pain $(n=50,28 \%)$ and, less frequently, headache $(n=20,11 \%)$, focal neurological deficit $(n=18,10 \%)$ and altered mental status $(n=13$, $7.2 \%$ ). The most common presumptive primary diagnoses were hypertension, heart failure or pulmonary oedema, stroke, acute coronary syndrome or myocardial infarction, and chest pain (Figure 2A).

The median (IQR) number of hours in the ED was 8.0 (4.0 to 20), the minimum ED stay was one-half hour and the maximum stay was 144 hours. Most ED patients ( $n=155,95 \%)$ had their IV antihypertensive treatment started in the ED; 9 patients (5.5\%) had it started in the ambulance; $4.4 \%$ experienced an episode of hypotension requiring discontinuation of the antihypertensive drug, and/or the administration of vasopressors or fluids, or reverse Trendelenburg positioning within 72 hours of starting treatment; and 3.3\% relapsed (requiring resumption of IV antihypertensive treatment) within 72 hours of discontinuation of the initial IV treatment.

The majority of the ED patients were admitted to a non-ICU inpatient unit ( $n=104,58 \%)$. Fifty-three patients (29\%) were discharged to home, 16 (8.9\%) were admitted to the ICU, 5 (2.8\%) left against medical advice and $2(1.1 \%)$ died in the ED.

\section{Perioperative patients}

The preoperative diagnoses of the 229 perioperative patients are shown in Figure 2B. Most operating or recovery room patients had undergone cardiac $(40 \%)$, gastrointestinal (17\%), orthopaedic $(11 \%)$ or vascular (9.2\%) surgery. The median duration of surgery was 190 minutes. Nearly one-half of the patients $(n=112,49 \%)$ had undergone cardiac surgery and were evaluated on the basis of their EuroSCORE (European System for Cardiac Operative Risk Evaluation; available at http:// www.euroscore.org/). The median score (IQR) was 2.5 (1.2 to 6.4; minimum 0 , maximum 68.6 ), which is equivalent to a median predicted mortality rate of $2.5 \%$ $(1.2 \%$ to $6.4 \%)$. For most patients $(n=143,67 \%)$ IV antihypertensive treatment started in the operating 
Table 3 Blood pressure, laboratory values, end-organ damage and outcomes (in-hospital)

\begin{tabular}{|c|c|c|c|c|}
\hline \multirow[t]{2}{*}{ Variables } & \multirow{2}{*}{$\begin{array}{l}\text { All patients } \\
(n=791)\end{array}$} & \multicolumn{3}{|c|}{ Enrolment setting } \\
\hline & & $\mathrm{ED}(n=180)$ & ICU $(n=382)$ & $\begin{array}{l}\text { Perioperative } \\
(n=229)\end{array}$ \\
\hline \multicolumn{5}{|l|}{ Median blood pressure, mmHg (IQR) } \\
\hline Qualifying SBP & $\begin{array}{l}166 \text { (141 to } \\
190)\end{array}$ & $200(174$ to 220$)$ & $160(138$ to 180$)$ & $\begin{array}{l}160(140 \text { to } \\
180)\end{array}$ \\
\hline Qualifying DBP & 80 (68 to 95$)$ & 100 (90 to 110$)$ & 73 (64 to 85) & 80 (68 to 90$)$ \\
\hline $\begin{array}{l}\text { Median time from qualifying BP to initiation of IV antihypertensive therapy, } \\
\text { minutes (IQR) }\end{array}$ & $5.0(2.0$ to 17$)$ & $20(5.0$ to 30$)$ & $5.0(1.0$ to 15$)$ & $5.0(1.0$ to 5.0$)$ \\
\hline Median time from IV initiation to $10 \%$ decrease in SBP, minutes (IQR) & $28(11$ to 60$)$ & 31 (18 to 87 ) & $30(12$ to 70$)$ & 18 (8.0 to 43$)$ \\
\hline \multicolumn{5}{|l|}{ Median laboratory values (IQR) } \\
\hline Peak troponin & $\begin{array}{l}0.03(0.01 \text { to } \\
0.23)\end{array}$ & $0.03(0.01$ to 0.12$)$ & 0.04 (0.01 to 0.33 ) & $\begin{array}{l}0.03(0.01 \text { to } \\
0.23)\end{array}$ \\
\hline Peak creatine kinase-MB & 33 (9.4 to 88 ) & 5.1 (3.8 to 78$)$ & 50 (31 to 152$)$ & 38 (24 to 79$)$ \\
\hline Peak NT-proBNP & $\begin{array}{l}910(295 \text { to } 2, \\
240)\end{array}$ & $\begin{array}{l}1,672(429 \text { to } 2, \\
637)\end{array}$ & $\begin{array}{l}1,451 \text { (428 to } 2 \\
709)\end{array}$ & $\begin{array}{l}359(242 \text { to } \\
970)\end{array}$ \\
\hline Peak BNP & 99 (82 to 132) & 116 (91 to 146$)$ & $20(20$ to 20$)$ & $\mathrm{n} / \mathrm{a}$ \\
\hline Initial creatinine, $\mu \mathrm{mol} / \mathrm{L}$ & 89 (72 to 113$)$ & 94 (78 to 125$)$ & 91 (74 to 116$)$ & 83 (69 to 102$)$ \\
\hline Peak creatinine, $\mu \mathrm{mol} / \mathrm{L}$ & $103(82$ to 146$)$ & 119 (99 to 222) & 107 (84 to 151$)$ & $92(73$ to 122$)$ \\
\hline \multicolumn{5}{|l|}{ End-organ injury ${ }^{\mathrm{a}}, n(\%)$} \\
\hline Acute coronary syndrome (new) & $25(3.2)$ & $22(12)$ & $2(0.5)$ & $1(0.4)$ \\
\hline Previous worsened & $10(1.3)$ & $8(4.4)$ & $2(0.5)$ & $0(0.0)$ \\
\hline Acute LV dysfunction/pulmonary oedema (new) & $28(3.5)$ & $19(11)$ & $7(1.8)$ & $2(0.9)$ \\
\hline Previous worsened & $20(2.5)$ & $16(8.9)$ & $4(1.1)$ & $0(0.0)$ \\
\hline Aortic dissection (new) & $5(0.6)$ & $2(1.1)$ & $3(0.8)$ & $0(0.0)$ \\
\hline Previous worsened & $2(0.3)$ & $1(0.6)$ & $1(0.3)$ & $0(0.0)$ \\
\hline Encephalopathy (new) & $22(2.8)$ & $8(4.4)$ & $11(2.9)$ & $3(1.3)$ \\
\hline Previous worsened & $2(0.3)$ & $1(0.6)$ & $0(0.0)$ & $1(0.4)$ \\
\hline Acute kidney failure (new) & $36(4.6)$ & $8(4.4)$ & $23(6.0)$ & $5(2.2)$ \\
\hline Previous worsened & $19(2.4)$ & $5(2.8)$ & $12(3.1)$ & $2(0.9)$ \\
\hline Stroke (new) & $13(1.6)$ & $8(4.4)$ & $5(1.3)$ & $0(0.0)$ \\
\hline Previous worsened & $7(0.9)$ & $3(1.7)$ & $2(0.6)$ & $2(0.9)$ \\
\hline \multicolumn{5}{|l|}{ Outcomes $n(\%)$} \\
\hline ICU admission & $114(14)$ & $17(9.4)$ & $19(5.0)^{b}$ & $78(34)$ \\
\hline Hypertension relapse & $104(13)$ & $14(7.8)$ & $55(14)$ & $35(15)$ \\
\hline
\end{tabular}

$\mathrm{BP}=$ blood pressure; DBP = diastolic blood pressure; ED = emergency department; IV = intravenous; LV = left ventricular; $\mathrm{n} / \mathrm{a}=$ not applicable; NT-proBNP = Nterminal prohormone of brain natriuretic peptide; SBP = systolic blood pressure. ${ }^{\mathrm{a} C a t e g o r i e s}$ are not mutually exclusive. ${ }^{\mathrm{b}} \mathrm{Readmission}$ to ICU.

room or theatre, and in $33 \%(n=71)$ it was begun after surgery. Postoperatively, $57 \%(n=130)$ of the patients were transferred to a postanaesthesia recovery area, $31 \%$ $(n=72)$ were transferred directly to the ICU and $12 \%$ $(n=27)$ were transferred directly to an inpatient ward or unit. Ten percent of patients experienced an episode of hypotension within 72 hours of starting treatment, and $4.8 \%$ of patients relapsed within 72 hours of the discontinuation of the initial IV treatment. Thirty-nine percent $(n=89)$ of patients received two or more different IV antihypertensive drugs.

\section{ICU patients}

Most ICU patients (304 of 382, 80\%) were direct postoperative admissions (that is, patients whose initial acute, severe hypertension developed after ICU admission). Their primary diagnoses are shown in Figure $2 \mathrm{C}$. The majority of patients in the ICU population were cardiac or cardiac surgery patients (62\%), $25 \%$ were mixed surgical and medical patients, $7 \%$ were surgical patients, $4 \%$ were medical patients and $3 \%$ were classified as 'other'. Patients spent a median (IQR) of 3 days (2 to 6 ) in the ICU. Among ICU patients, the minimum stay was 1 day and the maximum stay was 54 days. Thirteen patients $(3.4 \%)$ died in the ICU. The median time (IQR) in the ICU before IV treatment began was 3.4 hours ( 0.6 to 18$)$. Overall, $8.4 \%$ of ICU patients experienced an episode of hypotension within 72 hours of the start of IV antihypertensive treatment, $6.0 \%$ relapsed within 72 hours of discontinuation of the initial 


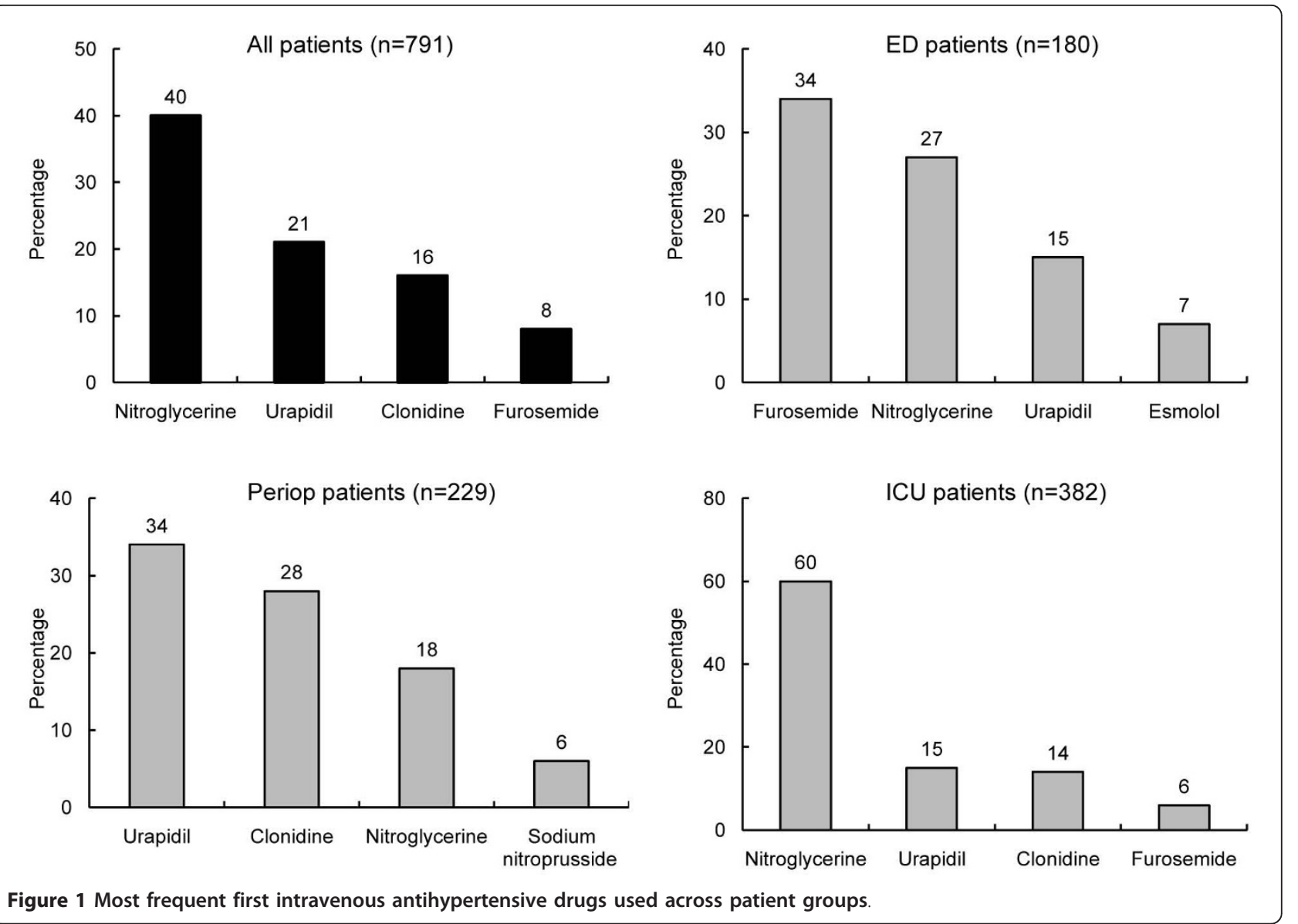

IV treatment, and $17 \%$ required treatment with more than one agent. Upon discharge, 90\% $(n=343)$ of the patients were transferred to an inpatient unit, $3.7 \%$ ( $n=$ 14) were transferred to another healthcare facility, $2.9 \%$ $(n=11)$ were discharged to home and $0.3 \%(n=1)$ left against medical advice.

\section{Thirty-day outcomes}

The overall rate of 30 -day death rate was $4 \%$, and the overall rate of new or worsening end-organ damage was $19 \%$. The rates of both outcomes were highest among patients in the ED ( $6 \%$ and $43 \%$, respectively), intermediate in the ICU patients ( $5 \%$ and $15 \%$, respectively) and lowest among patients in the perioperative setting ( $2 \%$ and $7 \%$, respectively).

\section{Discussion}

These contemporary data derived from the Euro-STAT study demonstrate heterogeneous patterns of care for patients presenting with acute elevation of BP across a range of acute care settings, with high rates of morbidity and mortality. Of the 791 patients included in EuroSTAT, $48 \%$ were treated for acute hypertension in the
ICU. Many of them had undergone surgery and developed severe hypertension postoperatively, 29\% developed it perioperatively and 23\% developed it in the ED. Median BP was higher among patients treated in the ED $(200 / 100 \mathrm{mmHg})$ than in those treated in the ICU (160/ $73 \mathrm{mmHg}$ ) or perioperatively $(160 / 80 \mathrm{mmHg})$.

The Studying the Treatment of Acute Hypertension (STAT) registry in the United States $[9,10]$ involved patients with a qualifying episode of acute, severe hypertension (that is, (1) SBP greater than 180 and/or DBP greater than $110 \mathrm{mmHg}$ or (2) SBP above $140 \mathrm{mmHg}$ and/or DBP greater than $90 \mathrm{mmHg}$ when presenting with subarachnoid haemorrhage) who received IV antihypertensive therapy in a critical care setting. Compared with the STAT study, the patients' median age in the Euro-STAT study was higher (69 vs 58 years) and fewer patients had a history of hypertension (62\% vs $89 \%)$. Overall, the median BP was lower in the Euro-STAT study than in the STAT study (166/80 vs $200 / 110$ $\mathrm{mmHg}$ ). This finding could indicate that patients in the Euro-STAT study had less severe hypertension, or it could be related to the different qualifying criteria and hence the distribution of patients in the STAT studies. 

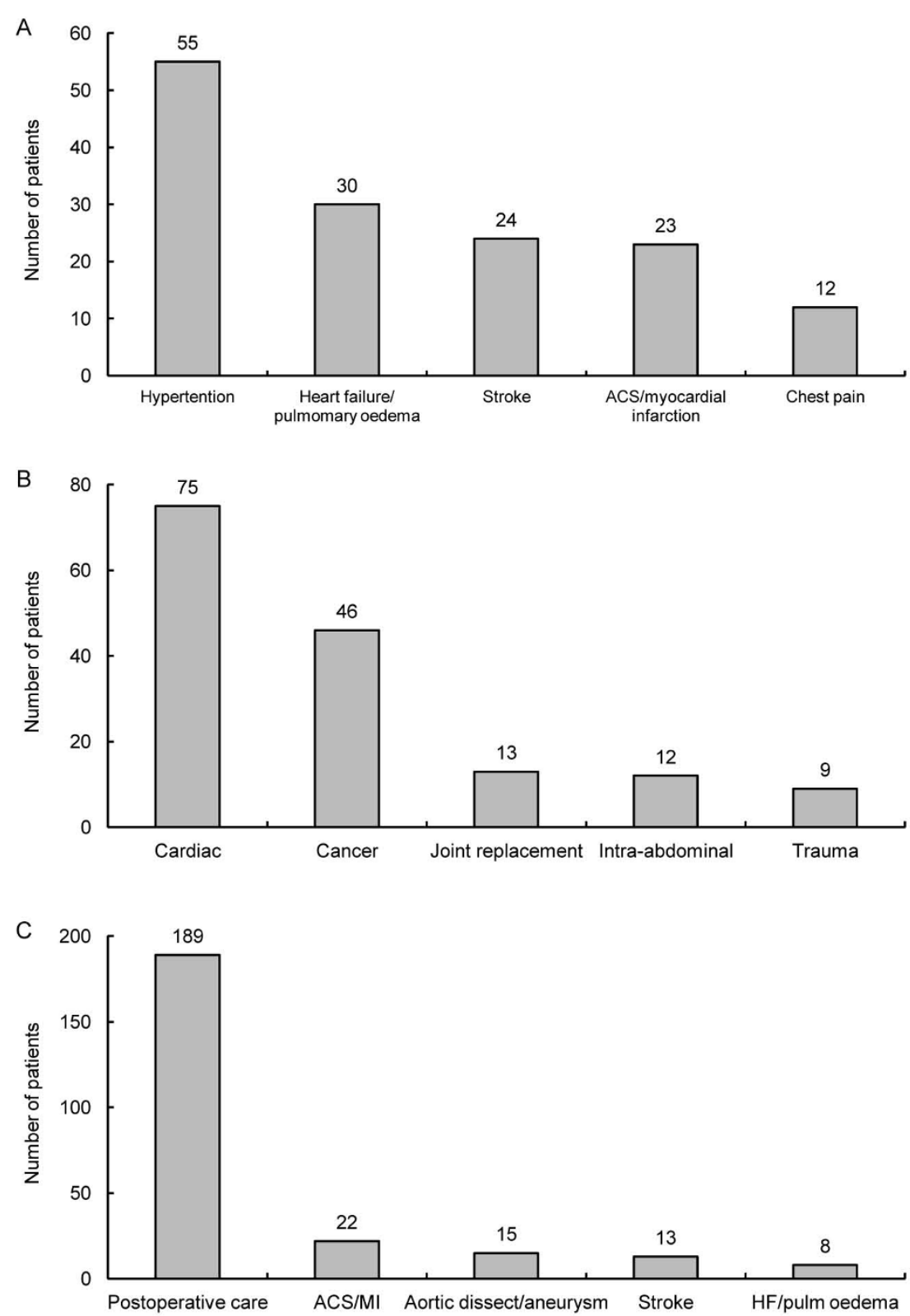

Figure 2 Presumptive primary admitting diagnoses. (A) Emergency department patients. (B) Perioperative patients. (C) ICU patients. ACS = acute coronary syndrome; $\mathrm{HF}$ = heart failure; $\mathrm{Ml}=$ myocardial infarction.

In Euro-STAT, perioperative patients were also included, and there were many more ICU patients (mainly in a postoperative context) than there were in the STAT study.

The decision to amalgamate ED, perioperative and ICU patients was made because the purpose of this descriptive study was to evaluate the efficacy of IV therapy for the control of elevated BP level in different locations within a hospital, thereby assessing similarities and differences in treatments and outcomes in different contexts.
The first antihypertensive drug used varied by treatment location. In the ICU, nitroglycerine was by far the most widely used (60\%); in the ED, furosemide was used in $34 \%$ of patients and nitroglycerine was used in $27 \%$; and perioperatively, urapidil was used in $34 \%$ of patients and clonidine was used in $28 \%$. The high use of furosemide in the ED (34\%) indicates that pulmonary oedema associated with high BP was the likely primary diagnosis, which is backed up by the higher rates of new or worsened acute coronary syndrome ( $17 \%$ vs $1.1 \%$ and $0.5 \%$ ) and acute left ventricular dysfunction (19.4\% vs $2.9 \%$ 
and $0.9 \%$ ) in ED vs ICU and perioperative patients, respectively. In Euro-STAT overall, the most frequently used antihypertensive drugs were nitroglycerine (40\%), urapidil (21\%), clonidine (16\%) and furosemide (8.3\%). This pattern is very different from the results of the STAT study, where the most common initial antihypertensive drugs were labetalol (32\%), metoprolol (17\%), nitroglycerine (15\%) and hydralazine (15\%) [9]. The variations in drug use between the Euro-STAT and STAT studies may reflect differences in the drugs available in these regions. The percentage of patients who required a second IV antihypertensive was $34 \%$ in both the EuroSTAT and STAT studies.

This variability in treatment between continents, studies and hospital departments is not surprising, given the paucity of evidence regarding the superiority of one drug over another and the absence of guidelines for the treatment of acute hypertension. There are, however, various papers that have provided recommendations that are not evidence-based. Acute hypertension can be split into hypertensive emergencies (severe BP elevation with evidence of impending or progressive end-organ damage) and hypertensive urgencies (severe BP elevation without progressive target organ dysfunction) [1]. In general, hypertensive urgencies can be treated with oral antihypertensive drugs [11], and researchers who published a recent meta-analysis found angiotensin-converting enzyme inhibitors to be superior to calcium channel blockers [12]. Hypertensive emergencies generally require IV treatment to achieve a rapid decrease in $\mathrm{BP}$, and patients admitted to these care settings may be sicker than patients treated with oral agents. Recommendations (based on expert consensus due to a lack of clinical trials) for which antihypertensive to use based on different disease states are shown in Table 4[13].

While nitroglycerine should be used as an adjunctive therapy, the high rates of use in the Euro-STAT population likely reflect familiarity with its use, together with its ease of administration, titration and rapid reversibility. In the ED, the ICU and perioperatively, 4.4\%, 8.4\% and $10 \%$ of patients, respectively, had hypotension within 72 hours of the start of treatment, resulting in (1) discontinuation of the antihypertensive drug or (2) treatment with vasopressors, fluids or reverse Trendelenburg positioning. The overall incidence of hypotension in the Euro-STAT study was higher than that in the STAT study (8.1\% vs $4.0 \%$ ) [9].

As expected, mortality rates at discharge from the ICU, ED or surgical department in the Euro-STAT study were highest among ICU patients $(3.4 \%$ vs $1.1 \%$ of ED patients and $0 \%$ of perioperative patients). Total inhospital mortality in the Euro-STAT study was highest among ED patients $(5.7 \%$ vs $5.1 \%$ of ICU patients and $2.3 \%$ of perioperative patients), which is lower than the comparable rate in the STAT study (6.9\%) [9]. New or worsened end-organ damage was observed in $43 \%$ of ED patients, $15 \%$ of ICU patients and $6.6 \%$ of perioperative patients.

\section{Limitations}

The observational Euro-STAT registry is a relatively small data set, and the sites may not be representative of all hospitals in Europe. Treatment choices may therefore be biased by institution choices. Also, populations of acute hypertension are heterogeneous and are likely to differ by country. Amalgamation of all countries into one data set therefore gives an overview, but no country-specific data. As our entry criteria required the physician to initiate IV antihypertensive therapy, there was no comparison with other patients in relation to morbidity. Also, we do not have complete information on post-hospital discharge follow-up. Furthermore, we do not know what happened to patients for whom a reduction in BP was not achieved despite treatment.

\section{Conclusions}

Acute hypertension is currently managed with a wide range of IV agents in the various clinical settings in which it arises. These patients have substantial concomitant morbidity and mortality, and IV antihypertensive treatment is associated with hypotension in almost $10 \%$ of patients. Further data are required to identify optimal

Table 4 Recommended treatments for hypertensive emergencies ${ }^{a}$

\begin{tabular}{|c|c|c|c|c|c|c|}
\hline Emergency type & Esmolol & Fenoldopam & Labetalol & Nicardipine & Nitroglycerine & Sodium nitroprusside \\
\hline Pulmonary oedema + systolic dysfunction & & Yes & & Yes & Yes $^{\mathrm{b}}$ & Yes \\
\hline Pulmonary oedema + diastolic dysfunction & Yes & & Yes & & $Y_{e s}^{b}$ & Yes \\
\hline Myocardial infarction & $\mathrm{Yes}^{\mathrm{c}}$ & & Yes $^{c}$ & & $Y_{e s}^{b}$ & \\
\hline Aortic dissection & Yes & & Yes & & & Yes \\
\hline Postoperative hypertension & Yes & & Yes & Yes & & \\
\hline Hypertensive encephalopathy & & Yes & Yes & Yes & & \\
\hline Kidney failure & & Yes & & Yes & & \\
\hline Stroke & & Yes & Yes & Yes & & \\
\hline
\end{tabular}

${ }^{a}$ Adapted from Smithburger et al. [13]. ${ }^{\mathrm{b}} \mathrm{As}$ adjunctive therapy. ${ }^{\mathrm{C}}$ In combination with intravenous nitroglycerine. 
management strategies for these patients, thereby ensuring the best possible outcomes.

\section{Key messages}

- High blood pressure requiring intravenously administered drug therapy is currently managed with a variety of agents in Europe, with the most commonly used being nitroglycerine, urapidil and clonidine.

- Intravenous antihypertensive treatment is associated with hypotension in almost $10 \%$ of patients.

- Patients with acute, severe hypertension have substantial concomitant morbidity and mortality.

\section{Abbreviations \\ BP: blood pressure; COR: Center for Outcomes Research; ED: emergency department; Euro-STAT: European registry for Studying the Treatment of Acute hyperTension.}

\section{Acknowledgements}

We thank the physicians and study coordinators participating in Euro-STAT and the staff at COR.

\section{Euro-STAT Steering Committee members}

Co-Chairs: Didier Payen de la Garanderie, Paris, France; Alain Vuylsteke, Cambridge, UK. Members: Frederick A Anderson, Worcester, MA, USA; Antonio Artigas, Sabadell, Spain; Jean-Daniel Chiche, Paris, France; A Raffaele De Gaudio, Florence, Italy; Salvatore Di Somma, Rome, Italy; Joel M Gore, Worcester, MA, USA; Christopher B Granger, Durham, NC, USA; Michael J Hiesmayr, Vienna, Austria; Andreas Hoeft, Bonn, Germany; Bengt Jönsson, Stockholm, Sweden; Andreas Koster, Berlin, Germany; Thomas Lüscher, Zurich, Switzerland; Jan Ostergren, Stockholm, Sweden; W Frank Peacock, Cleveland, OH, USA; Kees Polderman, Utrecht, The Netherlands; David Smith, Southampton, UK; Jean-Louis Vincent, Brussels, Belgium.

\section{Author details}

'Department of Anaesthesia \& Intensive Care, Papworth Hospital NHS Foundation Trust, Papworth Everard, Cambridge, CB23 3RE, UK. ${ }^{2}$ Department of Intensive Care, Erasme University Hospital, Route de Lennik 808 1070, University of Brussels, Brussels, Belgium. ${ }^{3}$ ''hôpital Lariboisière, 2 Rue Ambroise Paré, 75475 Paris Cedex 10 Assistance publique-Hôpitaux de Paris (AP-HP), Université Paris Diderot-Paris 7, Paris, France. ${ }^{4}$ Center for Outcomes Research, University of Massachusetts Medical School, One Innovation Drive, Suite 110 Worcester, MA 01605 USA. ${ }^{5}$ Department of Quantitative Health Sciences, University of Massachusetts Medical School, 55 Lake Avenue North, Worcester, MA 01655 USA.

\section{Authors' contributions}

The Euro-STAT Steering Committee was responsible for the design and scientific and ethical conduct of the study, including assurance that appropriate measures for the protection of the participants, including hospitals, physicians and patients, were instituted and followed consistently. $A V$, JLV, DPG, FAA and JMG were fully involved in the design and conduct of the study, had access to all study analyses, drafted and edited the paper and agreed upon its final contents.

\section{Competing interests}

The Euro-STAT study was supported by a grant from The Medicines Company to the COR at the University of Massachusetts Medical School. All authors have connections to The Medicines Company (Parsippany, NJ, USA). All authors were either employees of, or consultants to, the Center for Outcomes Research, University of Massachusetts Medical School (UMMS), which received a contract from TMC to perform this work.

Received: 29 July 2011 Revised: 15 November 2011 Accepted: 16 November 2011 Published: 16 November 2011

\section{References}

1. Chobanian AV, Bakris GL, Black HR, Cushman WC, Green LA, Izzo JL Jr, Jones DW, Materson BJ, Oparil S, Wright JT Jr, Roccella EJ, Joint National Committee on Prevention, and Treatment of High Blood Pressure. National Heart, and Blood Institute, National High Blood Pressure Education Program Coordinating Committee: JNC 7: Complete report. Seventh Report of the Joint National Committee on Prevention, Detection, Evaluation, and Treatment of High Blood Pressure. Hypertension 2003, 42:1206-1252.

2. Rosamond W, Flegal K, Furie K, Go A, Greenlund K, Haase N, Hailpern SM, Ho M, Howard V, Kissela B, Kittner S, Lloyd-Jones D, McDermott M, Meigs J, Moy C, Nichol G, O'Donnell C, Roger V, Sorlie P, Steinberger J, Thom T, Wilson M, Hong Y, American Heart Association Statistics Committee and Stroke Statistics Subcommittee: Heart disease and stroke statistics-2008 update: a Report from the American Heart Association Statistics Committee and Stroke Statistics Subcommittee. Circulation 2008, 117: e25-e146.

3. Lawes CM, Rodgers A, Bennett DA, Parag V, Suh I, Ueshima H, MacMahon S, Asia Pacific Cohort Studies Collaboration: Blood pressure and cardiovascular disease in the Asia Pacific region. J Hypertens 2003, 21:707-716.

4. Lewington S, Clarke R, Qizilbash N, Peto R, Collins R, Prospective Studies Collaboration: Age-specific relevance of usual blood pressure to vascular mortality: a meta-analysis of individual data for one million adults in 61 prospective studies. Lancet 2002, 360:1903-1913, A published erratum appears in Lancet 2003, 361:1060.

5. MacMahon S, Peto R, Cutler J, Collins R, Sorlie P, Neaton J, Abbott R, Godwin J, Dyer A, Stamler J: Blood pressure, stroke, and coronary heart disease. Part 1, Prolonged differences in blood pressure: prospective observational studies corrected for the regression dilution bias. Lancet 1990, 335:765-774

6. Wiederkehr M, Toto R, Fenves AZ, Ram CV: Hypertension and the kidney. Semin Nephrol 2005, 25:236-245.

7. Cherney D, Straus S: Management of patients with hypertensive urgencies and emergencies: a systematic review of the literature. J Gen Intern Med 2002, 17:937-945.

8. Zampaglione B, Pascale C, Marchisio M, Cavallo-Perin P: Hypertensive urgencies and emergencies. Prevalence and clinical presentation. Hypertension 1996, 27:144-147.

9. Katz JN, Gore JM, Amin A, Anderson FA, Dasta JF, Ferguson JJ, Kleinschmidt K, Mayer SA, Multz AS, Peacock WF, Peterson E, Pollack C, Sung GY, Shorr A, Varon J, Wyman A, Emery LA, Granger CB, on behalf of the STAT Investigators: Practice patterns, outcomes, and end-organ dysfunction for patients with acute severe hypertension: The Studying the Treatment of Acute hyperTension (STAT) Registry. Am Heart J 2009, 158:599-606, e1.

10. Gore JM, Peterson E, Amin A, Anderson FA Jr, Dasta JF, Levy PD, O'Neil BJ, Sung GY, Varon J, Wyman A, Granger CB, for the STAT Investigators: Predictors of 90-day readmission among patients with acute severe hypertension: The cross-sectional observational Studying the Treatment of Acute hyperTension (STAT) study. Am Heart J 2010, 160:521-527, e1.

11. Rodriguez MA, Kumar SK, De Caro M: Hypertensive crisis. Cardiol Rev 2010, 18:102-107.

12. Souza LM, Riera R, Saconato H, Demathé A, Atallah AN: Oral drugs for hypertensive urgencies: systematic review and meta-analysis. Sao Paulo Med J 2009, 127:366-372

13. Smithburger PL, Kane-Gill SL, Nestor BL, Seybert AL: Recent advances in the treatment of hypertensive emergencies. Crit Care Nurse 2010, 30:24-31.

doi:10.1186/cc10551

Cite this article as: Vuylsteke et al.: Characteristics, practice patterns, and outcomes in patients with acute hypertension: European registry for Studying the Treatment of Acute hyperTension (Euro-STAT). Critical Care 2011 15:R271. 